\title{
Dewey, Dilthey e Drama: um ensaio em Antropologia da Experiência (primeira parte), de Victor Turner*
}

TRADUÇÃO

\section{Herbert Rodrigues}

Mestrando em Antropologia Social pelo PPGAS/ FFLCH-USP e membro do Núcleo de Antropologia da Performance e do Drama (NAPEDRA/ USP). ${ }^{* *}$
De todos os estudos e ciências humanas, a antropologia é a que está mais profundamente enraizada na experiência social e subjetiva do investigador. Nela, toda avaliação tem como referência o sujeito, toda observação é finalmente apreendida "na batida do pulso". Evidentemente, muitas coisas podem ser mensuradas, consideradas, contadas e submetidas à análise estatística. Porém, todos os atos humanos estão impregnados de significado, e significado é difícil de ser mensurado, embora possa ser compreendido, mesmo que apenas de modo fugaz e ambíguo. $\mathrm{O}$ significado surge quando tentamos associar o que a cultura e a língua cristalizaram a partir do passado com o que sentimos, desejamos e pensamos em relação ao instante presente da vida. Em outras palavras, retomamos as conclusóes que nossos ancestrais estabeleceram como modos culturais

* TURNER, Victor. 1986. "Dewey, Dilthey, and Drama: An Essay in the Anthropology of Experience" In Turner, Victor W. \& Bruner, Edward M. (eds.) The Anthropology of Experience. Urbana and Chicago, University of Illinois Press, pp. 33-44.

** Agradeço a Evelise Paulis, a André-Kees de Moraes Schouten e a Danilo Paiva Ramos pela colaboraçáo na tradução.
REVISÃO

John C. DAWSEY

Professor Livre-Docente do Departamento de Antropologia da FFLCH-USP e coordenador do Núcleo de Antropologia da Performance e do Drama (NAPEDRA/USP).

que classificamos hoje, dentro da tradição ocidental, como "religiosos", "morais", "políticos", "estéticos”, "proverbiais", "aforísticos”, de "senso comum" etc., para ver como e em que medida essas conclusóes iluminam ou se relacionam com as nossas questóes, dificuldades, problemas, ou alegrias individuais do presente. Cada movimento de fricção entre as madeiras duras e brandas da tradição e do presente é potencialmente dramático. Em caso de venerarmos ditos ancestrais, talvez seja preciso - concluimos com pesar - desfazer-nos das alegrias do presente ou abandonar a exploraçáo sensível do que percebemos como desenvolvimentos sem precedentes do entendimento humano mútuo e das formas relacionais.

Conseqüentemente, teremos o auto-sacrifício por um ideal, se tivermos fé na autoridade de uma cultura herdada do passado. Mas se a tragédia aprova essa postura, os novos caminhos de orientaçáo para a modernidade podem rejeitar o resultado do auto-sacrifício e sugerir alternativas que podem parecer problemáticas, pelo menos para um público geral ainda não saído do confortável berço da tradição. Uma experiência desse tipo é da própria natureza do drama - tanto do drama social, onde os confli- 
tos são trabalhados na ação social, quanto do drama de palco, onde eles se espelham numa multiplicidade de enredos hipotéticos, símbolos, e enquadramentos estéticos experimentais. Entretanto, é possível que não haja nenhum confronto absoluto entre o passado e o presente, o passado coletivo e o presente pessoal e existencial. Todo antropólogo sabe que qualquer campo sociocultural coerente contém muitos princípios contraditórios, todos consagrados pela tradição. No teatro japonês, por exemplo, as versóes Bunraku e Kabuki de Chushingura, a famosa fábula dos quarenta e nove Rōnin, mostram a tensão entre duas lealdades igualmente axiomáticas, mas conflitantes - uma para com o senhor feudal e outra para com a ordem imperial. A obediência a ambos poderia significar a morte aos detentores da vingança. A subordinação da lealdade feudal à lei do estado poderia ter sido uma perda humilhante de identidade social formada sob os princípios samurai de honra e de vergonha. Mas, algo subversivo e oculto ocorre no drama de palco. A burocracia Tokugawa, com sua extensa despersonalização das relaçóes, está sendo silenciosamente respondida por gestos marcantes e complexos do teatro que reafirmam as paixóes contra as legalizaçóes - aquelas grandes paixóes que Samuel Coleridge, referindo-se aos heróis trágicos shakespearianos, declarou serem "ateus que acreditavam em nenhum futuro". No entanto, as paixóes estão sob controle e chegam a uma honrosa consumação através de um emaranhado de meios tortuosos - e de modos que poderiam ter chocado Aldous Huxley, com seu dito de que "maus meios náo produzem bons fins". Isso, se ele não fosse um homem com capacidade para a ironia e consciente das ambigüidades éticas.

Passemos agora para a visão de John Dewey sobre a experiência, da qual parcialmente compartilho, mas que - devo parcialmente concluir - precisa ser superada em relação a um importante aspecto. Dewey (1934) sustentou que as obras de arte, incluindo obras teatrais, são "celebraçóes, reconhecidas como tais, da experiência cotidiana” (ordinary experience). Ele estava, evidentemente, rejeitando a tendência nas sociedades capitalistas de colocar a arte num pedestal, separada da vida humana, mas comercialmente valiosa dentro de normas estabelecidas por especialistas esotéricos. Dewey disse: "Até mesmo uma experiência simples, se for uma experiência autêntica, é mais adequada para dar uma pista à natureza intrínseca da experiência estética do que um objeto já colocado à parte de qualquer outro modo de experiência" (citado em McDermott 1981: 526). Tudo isso e mais a esse respeito encontra-se no seu grande livro Art as Experience, publicado quando Dewey tinha setenta e cinco anos de idade.

Em meu livro From Ritual to Theatre (1982: 17-18), ensaiei uma etimologia da palavra inglesa "experiência", derivando-a da base indoeuropéia *per-, "tentar, aventurar-se, arriscar" - podemos ver como seu duplo, "drama", do grego dran, "fazer", espelha culturalmente o "perigo" etimologicamente implicado na palavra "experiência". O cognato germânico de per relaciona experiência com "passagem", "medo" e "transporte", porque $p$ torna-se $f$ na Lei de Grimm. O grego peraō relaciona experiência a "passar através", com implicaçóes em ritos de passagem. Em grego e latim, experiência associa-se a perigo, pirata e ex-per-imento.

Há aqui uma dicotomia que Wilhelm Dilthey (1979 [1914]: 210) imediatamente captou na sua distinção entre mera "experiência" e "uma experiência”. A mera experiência é, simplesmente, a passiva resignação e aceitação dos eventos. "Uma experiência", como uma pedra num jardim de areia Zen, destaca-se da uniformidade da passagem das horas e dos anos e forma aquilo que Dilthey chamou de uma "estrutura da experiência”. Em outras palavras, ela não tem um início ou um fim arbitrários, recor- 
tados do fluxo da temporalidade cronológica, mas tem o que Dewey chamou de "uma iniciaçáo e uma consumaçáa”. Ao longo da vida, cada um de nós já teve certas "experiências" que foram formativas e transformativas, isto é, seqüências distinguíveis de eventos externos e de reações internas a eles tais como iniciaçóes em novos modos de vida (o primeiro dia na escola, o primeiro emprego, entrada no exército, cerimônia de casamento), aventuras amorosas, o envolvimento naquilo que Emile Durkheim chamou de "efervescência social" (uma campanha política, uma declaração de guerra, uma causa célèbre tais como o caso Dreyfus, o Watergate, a crise dos reféns iranianos ou a Revolução Russa). Algumas dessas experiências formativas são altamente pessoais, outras são partilhadas com grupos aos quais pertencemos por nascimento ou escolha. Dilthey via tais experiências como tendo uma estrutura temporal ou processual - elas são "processadas" através de estágios distinguíveis. Além disso, elas envolveram em suas estruturaçôes, a cada momento e fase, não simplesmente uma estruturaçáo do pensamento, mas a totalidade do repertório vital humano que inclui pensamento, vontade, desejo e sentimento, sutil e variavelmente interpenetrante em muitos níveis. Uma navalha cognitiva de Occam, reduzindo tudo a abstraçóes frias e "sem sangue" (isso se pudermos visualizar uma navalha nesses termos), simplesmente não faria nenhum sentido humano nesse caso.

Essas experiências que interrompem o comportamento rotinizado e repetitivo - do qual elas irrompem -, iniciam-se com choques de dor ou prazer. Tais choques são evocativos: eles invocam precedentes e semelhanças de um passado consciente ou inconsciente - porque o incomum tem suas tradiçóes, assim como o comum. Então, as emoçóes de experiências passadas dão cor às imagens e esboços revividos pelo choque no presente. Em seguida ocorre uma necessidade ansiosa de encontrar signifi- cado naquilo que se apresentou de modo desconcertante, seja através da dor ou do prazer, e que converteu a mera experiência em uma experiência. Tudo isso acontece quando tentamos juntar passado e presente.

É estruturalmente irrelevante se o passado é "real" ou "mítico", "moral" ou "amoral". A questão é se diretrizes significativas emergem do encontro existencial na subjetividade, daquilo que derivamos de estruturas ou unidades de experiência prévias numa relação vital com a nova experiência. Isso é uma questão de significado, não meramente de valor, como Dilthey entendia esses termos. Para ele, o valor pertencia essencialmente a uma experiência num presente consciente, em seu prazer afetivo ou no fracasso deste. Mas os valores não estão significativamente conectados, eles nos bombardeiam como amontoados aleatórios de discórdias e harmonias. Cada valor nos ocupa totalmente enquanto prevalece. No entanto, para Dilthey, os valores não têm "uma relação musical um com o outro". É somente quando relacionamos a preocupante experiência atual com os resultados cumulativos de experiências passadas - se não semelhantes, pelo menos relevantes e de potência correspondente - que emerge o tipo de estrutura relacional chamada "significado".

Aqui, o cognitivo se auto-afirma heroicamente, pois na maioria das experiências, a emoção e o desejo têm preeminência no início, em pulsos que repudiam todo o passado. Quando uma guerra é declarada; quando encontramos o mais desejável amor; quando fugimos do perigo físico; ou recusamos nos submeter a uma tarefa necessária, mas desagradável -, estamos sob o poder do valor. É a heróica combinação de vontade e de pensamento que se opóe ao valor por meio do poder integrativo do significado relacional. Talvez o valor poderá se transformar em significado, mas terá de ser, primeiramente, peneirado de maneira responsável. $\mathrm{Na}$ maioria 
das sociedades pré-industriais, essa busca árdua pelo significado foi poderosamente reforçada pelos valores culturais coletivos que ofereciam às nossas faculdades cognitivas algum suporte ancestral, o peso de um passado, senáo ético, pelo menos legitimado consensualmente. Nos dias de hoje, infelizmente, a cultura insiste que devemos assumir o fardo pós-renascentista de elaborar cada significado por nós mesmos, um de cada vez, sem ajuda dos outros, a menos que escolhamos um sistema tecido por outro indivíduo cuja legitimidade coletiva não é maior que a nossa. Essa é, possivelmente, uma diferença importante entre o teatro de hoje e os primeiros tipos de teatro, na medida em que o teatro se oferece como espelho cultural do processo de busca de significado num nível público e generalizado. As primeiras formas de teatro transferiram o peso da responsabilidade de atribuição de significado do indivíduo para o grupo, embora o sofrimento trágico então tenha resultado do terror físico do indivíduo, ou pelo menos da relutância extrema face ao dever social cujo cumprimento poderia significar tormento físico ou mental e até a morte.

$\mathrm{Na}$ visão de Dilthey, a experiência incita a expressão, ou a comunicação, com os outros. Somos seres sociais e queremos dizer o que aprendemos com a experiência. As artes dependem desse ímpeto para confessar e declamar. Os significados obtidos às duras penas devem ser ditos, pintados, dançados, dramatizados, enfim, colocados em circulaçáo. Aqui o ímpeto do paváo para exibir-se náo se distingue da necessidade ritualizada de se comunicar. $\mathrm{O}$ eu e o não-eu, o ego e o não-ego, a auto-afirmação e o altruísmo, encontram-se e se fundem em comunicaçóes significativas.

Subjacente a todas as artes, Dewey viu uma conexão intrínseca entre a experiência, seja ela natural ou social, e a forma estética. Ele escreveu: "há na natureza, mesmo que abaixo do nível da vida, algo além do mero fluxo e da mudança. A forma se apresenta sempre que um equilíbrio estável, embora em movimento, seja alcançado" (citado em McDermott 1981: 536). Ele argumenta que, mesmo no nível préhumano biológico, a vida de qualquer organismo é enriquecida pelo estado de disparidade e resistência por qual passou com sucesso. A oposiçáo e o conflito são superados e, de fato, transformados "em aspectos diferenciados de uma vida potencializada e mais significativa". Entre os humanos, o

ritmo da perda de integraçáo com o meio ambiente e a recuperação da uniáo, não apenas persiste, mas torna-se consciente com ele; suas condiçôes são materiais a partir das quais ele elabora propósitos. A emoção é o sinal consciente de uma ruptura, atual ou iminente. $\mathrm{O}$ desejo de restauração da união converte a mera emoção em interesse por objetos como condição de realizar a harmonia. Com a realização, o material de reflexáo é incorporado aos objetos como o seu significado. Considerando-se que o artista tem um cuidado peculiar com a fase de experiência em que a uniáo é alcançada, ele náo evita os momentos de resistência e de tensão. Ele antes os cultiva, não por razóes intrínsecas, mas por causa de suas potencialidades, trazendo para a consciência viva uma experiência que é total e una. Em contraste com a pessoa cujo propósito é estético, o cientista está interessado em problemas, em situaçóes em que a tensão entre a matéria da observaçáo e do pensamento é marcante. Claro, ele se interessa por sua resolução. Mas não se acomoda; passa para um outro problema fazendo uso de uma soluçáo anteriormente obtida como quem busca um ponto de partida para novas investigaçôes....

A diferença entre o esteta e o intelectual é, portanto, um dos lugares onde a ênfase recai no ritmo constante que marca a interação das criaturas vivas com o seu ambiente. A questão fundamental de ambas as ênfases na experiência 
é a mesma, como é também a sua forma geral. A idéia esquisita de que um artista não pensa e de que um cientista não faz outra coisa senão pensar é o resultado da conversão de uma diferença de andamento e de ênfase numa diferença de tipo. $\mathrm{O}$ pensador tem seu momento estético quando suas idéias deixam de ser meras idéias e transformam-se em significados corporificados, em objetos. $\mathrm{O}$ artista tem seus problemas e pensa enquanto trabalha. Mas seu pensamento é mais imediatamente incorporado no objeto. Por conta do distanciamento comparativo de seu fim, o cientista opera com símbolos, palavras e signos matemáticos. $\mathrm{O}$ artista realiza seu pensamento nos próprios meios qualitativos com quais ele trabalha, e os termos situam-se tão próximos ao objeto que ele está produzindo que se fundem diretamente neste....

Considerando-se que o mundo real, o mundo onde vivemos, é uma combinação de movimento e culminação, de rupturas e reuniôes, a experiência de uma criatura viva é capaz de ter uma qualidade estética. O ser vivo perde e re-estabelece, de modo recorrente, o equilíbrio com o ambiente. $O$ momento de passagem do distúrbio para a harmonia é o mais intenso na vida. Num mundo acabado, não seria possível distinguir entre o sono e a vigília. Num mundo totalmente perturbado, não seria possível sequer lutar com as condiçóes. Num mundo feito de acordo com os padróes daquele que conhecemos, os momentos de realização pontuam a experiência em intervalos rítmicos (citado em McDermott 1981: 536-537, grifos meus).

A estética, então, refere-se àquelas fases que, numa dada estrutura ou unidade processual de experiência, ou constituem uma realização que atinge as profundezas do ser (como Dewey coloca) de quem tem uma experiência, ou constituem os obstáculos e falhas que necessariamente fazem parte da alegre luta para alcançar a consumação, além do prazer e do equilíbrio - onde se encontra a verdadeira alegria e felicidade da realização. Há também presente no trabalho de Dewey o sentido de que o "tempo de consumação é também do recomeço" - qualquer tentativa de prolongar o prazer de consumaçáo para além de seu termo natural implica um tipo de retirada do mundo e, portanto, uma diminuição e perda de vitalidade.

A unidade de experiência de Dilthey enfatiza a cultura e a psicologia, pois ele viu a busca pelo significado e sua expressão na performance como manifestaçóes das fases de luta e consumação. Em Dewey, o processo de experiência tendia mais para o biológico. No entanto, ambos enfatizaram que a estética tem sua gênese na experiência humana sensível e não procede de um domínio ideal, ou de um reino platônico de arquétipos superiores às atividades humanas vulgares que, supostamente, ele deveria avaliar e organizar. Para os dois filósofos, as artes, incluindo todos os gêneros de teatro, têm suas origens nas cenas e objetos da experiência humana, e não poderiam ser consideradas à parte deles. O belo é a flor consumada da busca desordenada de significado pelos homens e mulheres que vivem na complexidade plena de sua mútua atração e repulsão na guerra, no culto, no sexo, na produçáo econômica e no mercado.

Como alguns sabem, tenho concentrado meu trabalho num tipo específico de unidade de experiência, a qual chamo de "drama social". Trata-se, em seus desdobramentos, de uma forma proto-estética. Em muitas situaçóes de pesquisa de campo em culturas notavelmente diferentes, na minha experiência de vida em sociedades ocidentais, e em numerosos documentos históricos, podemos claramente discernir o movimento de uma comunidade através do tempo como tomando uma forma à qual dificilmente podemos negar o epíteto “dramático". Uma pessoa ou sub-grupo quebra uma regra, deliberadamente ou por compulsão 
interior, num contexto público. Os conflitos entre os indivíduos, setores e facçôes seguem à ruptura original, revelando embates ocultos de caráter, interesses e ambiçóes. Estes resultam numa crise de unidade e continuidade do grupo, a menos que sejam rapidamente bloqueados por uma açáo pública reparadora, consensualmente empreendida por líderes, guardióes, ou membros mais velhos do grupo social. A ação reparadora é freqüentemente ritualizada e pode ser empreendida em nome da lei ou da religiáo. Os processos judiciais acentuam a razão e a evidência; os processos religiosos enfatizam as questóes éticas, as maldiçóes ocultas que operam através de bruxarias, ou a ira dos ancestrais contra as quebras de tabu ou a impiedade dos vivos em relação aos mortos. Se um drama social percorrer seu curso completo, o resultado (ou "consumaçáo", como Dewey diria) pode se manifestar através ou da restauração da paz e "normalidade" entre os participantes ou do reconhecimento social de uma ruptura ou cisão irremediável.

Claro, esse modelo, como todos os modelos, está sujeito a muitas manipulaçôes. Por exemplo, a açáo reparadora pode falhar, e nesse caso haverá um retorno à fase da crise. Se a lei e/ou os valores religiosos perderem sua eficácia, um faccionalismo contínuo e endêmico poderá contaminar a vida pública por longos períodos. Ou o fracasso de uma ação reparadora numa comunidade local poderá levar a apelos a instâncias superiores situadas em níveis mais inclusivos de organização social - da aldeia ao distrito à província à nação. $\mathrm{Ou}$ o ancien régime pode ser rejeitado in toto, dando início à revoluçáo. Nesse caso, o grupo poderá ser radicalmente reestruturado, incluindo sua maquinaria reparadora.

A cultura evidentemente afeta tais aspectos, como o estilo e o andamento do drama social. Algumas culturas procuram retardar as deflagraçóes de crise aberta elaborando regras sofisticadas de etiqueta. Outras admitem o uso de violência organizada na crise ou como açáo reparadora, como se pode verificar em exemplos tais como o holmgang dos islandeses (combate individual na ilha), a luta com varas dos Nuba do Sudão, e as recíprocas expediçóes dos caçadores de cabeças dos povos da colina Ilongot em Luzon. Georg Simmel, Lewis Coser, Max Gluckman e outros indicaram como o conflito - desde que colocado sob controle, evitando-se o massacre e a guerra - pode inclusive realçar a "consciência de pertencimento" a um grupo. $\mathrm{O}$ conflito força os antagonistas a diagnosticarem as suas causas e, assim fazendo, a se tornarem plenamente conscientes dos princípios que os unem para além e acima das questôes que os cindiram temporariamente. Como insistiu Durkheim, a lei precisa do crime e a religiáo precisa do pecado para se tornarem sistemas plenamente dinâmicos, porque, sem "o fazer", sem a fricçáo social que acende a consciência e a auto-consciência, a vida social seria passiva e até inerte.

Essas considerações, acredito, levaram Barbara Myerhoff (1979) a distinguir "cerimônias definitórias" de "dramas sociais", que ela concebeu como um tipo de "auto-biografia" coletiva, um meio pelo qual um grupo cria sua identidade ao contar para si uma história sobre si mesmo, um processo ao longo do qual ganha vida a "sua Identidade Determinada e Definida" (para citar William Blake). Aqui, no sentido diltheyniano, o significado é engendrado pela articulaçáo de problemas presentes a um rico passado étnico, que então é infundido nos "feitos e provaçôes" (frase de Dewey) da comunidade local. Alguns dramas sociais podem ser mais "definitórios" do que outros, isso é certo, mas muitos dramas sociais contêm, mesmo que apenas implicitamente, meios de reflexividade pública em seus processos reparadores. Ao ativá-los, os grupos avaliam a sua situação atual: a natureza e a força de seus laços sociais, o poder 
de seus símbolos, a eficácia de seus controles morais e legais, a sacralidade de suas tradiçôes religiosas, e assim por diante.

O ponto que eu gostaria de ressaltar aqui é que o mundo do teatro, como nós o conhecemos tanto na Ásia como no Ocidente, e a imensa variedade de sub-gêneros teatrais, derivam não da imitação, consciente ou inconsciente, da forma processual do drama social completo ou saciado - ruptura, crise, reparação, reintegração, ou cisão (embora o modelo de tragédia de Aristóteles se assemelhe a esse movimento seqüencial), mas especificamente da terceira fase, reparação, e, especialmente, da reparação como processo ritual. Os rituais reparadores incluem adivinhaçóes a respeito das causas escondidas de infortúnios, conflitos e doenças (todos estes, em sociedades tribais, estando intimamente interconectados e diagnosticados como sendo gerados por açóes de espíritos invisíveis, deidades, bruxos e feiticeiros), rituais curativos (que podem freqüentemente envolver episódios de possessão de espíritos, transe xamânico, mediunidade, e estados de transe entre os pacientes que são os participantes de um ritual), e os ritos iniciatórios relacionados aos "rituais de aflição". Além disso, muitos dos ritos que chamamos de "cerimônias de crise da vida", particularmente os de puberdade, casamento e morte, indicam, eles mesmos, uma espécie de ruptura na ordem costumeira da vida grupal, depois da qual muitos relacionamentos entre os membros do grupo devem mudar drasticamente, envolvendo muita competição e conflitos potenciais, e até mesmo reais (por direitos de herança e sucessão, por mulheres, pelos dotes da noiva, lealdade ao clá ou à linhagem, entre outras coisas). Os rituais de crise da vida (assim, aliás, como os rituais sazonais) podem ser chamados de "profiláticos", enquanto rituais de aflição são "terapêuticos".

Todos esses processos rituais de "terceirafase" ou "primeira-fase" (no caso de crise da vida) contêm uma fase liminar, que fornece um estágio $^{1}$ (uso esse termo advertidamente) para estruturas únicas de experiências (o Erlebnis de Dilthey) em meios isolados da vida mundana e caracterizados pela presença de idéias ambíguas, imagens monstruosas, símbolos sagrados, provaçóes, humilhaçóes, instruçóes paradoxais e esotéricas, a emergência de tipos simbólicos representados por palhaços e mascarados, inversóes de gêneros, anonimatos e muitos outros fenômenos e processos que tenho descrito em outros textos como "liminares". O limen, ou limiar $^{2}$ - um termo emprestado da segunda das três fases dos ritos de passagem de van Gennep - é uma terra-de-ninguém entre ${ }^{3}$ o passado estrutural e o futuro estrutural, tal como antecipado pelo controle normativo da sociedade sobre o desenvolvimento biológico. Isso é ritualizado de muitas formas, mas freqüentemente os símbolos que expressam uma identidade ambígua são encontrados numa variedade expressiva de culturas: figuras andróginas e teriomórficas, ${ }^{4}$ combinaçóes monstruosas de elementos retirados da cultura e da natureza, com alguns símbolos tais como cavernas, representando nascimento e morte, útero e túmulo. Às vezes, falo sobre a fase liminar como algo que predomina no modo subjuntivo da cultura, o modo do "talvez", do "pode ser", do "como se", hipótese, fantasia, conjectura, desejo - dependendo de qual elemento da trindade de cognição, afeto e vontade está situacionalmente dominante. A vida cotidiana acontece no modo indicativo, em meio à expectativa da operaçáo invariante de causa e efeito, do senso comum e racionalidade. A liminaridade pode talvez ser descrita como um caos frutífero, um armazém de possibilidades, não uma

1. Turner usa o termo stage, que também quer dizer "palco" (N. da R.).

2. Turner usa o termo threshold (N. da R.).

3. Turner usa a expressão betwixt and between (N. da R.).

4. Turner usa o termo theriomorphic (N. da R.). 
montagem aleatória, mas uma busca por novas formas e estruturas, um processo de gestação, uma irrupção fetal de modos apropriados de existência pós-liminar.

O teatro é uma dessas muitas herdeiras do grande sistema multifacetado que chamamos de "ritual tribal", que abrange idéias e imagens do cosmos e do caos, interdigitando palhaços e suas folias com deuses e suas solenidades, e fazendo uso de todos os códigos sensoriais para produzir sinfonias para além da música: o entrelaçamento da dança, de diferentes tipos de linguagens corporais, cançôes, cânticos, formas arquitetônicas (templos e anfiteatros), incensos, oferendas, banquetes ritualizados, pinturas, tatuagens, circuncisóes, escarificações, e marcaçôes corporais de muitos tipos, a aplicação de loções e a ingestão de poções, a encenação de tramas míticos e heróicos retirados de tradiçóes orais - e muito mais. Os rápidos avanços na escala e complexidade da sociedade, particularmente após a industrializaçáo, fizeram passar essa configuração liminar unificada pelo prisma da divisão do trabalho, com suas especializaçóes e profissionalizaçôes, reduzindo cada um dos seus domínios sensoriais a um conjunto de gêneros de entretenimento que florescem no tempo de lazer da sociedade, não mais no lugar central de controle. Apesar do fato de que o pronunciado caráter sobrenatural do ritual arcaico tem sido grandemente reduzido, há sinais, no presente, entre gêneros especializados amputados, de uma busca para recuperar algo da experiência do numinoso, que se perdeu em seu sparagmos, ou desmembramento.

Claramente, como Dewey argumentou, a forma estética do teatro é inerente à própria vida sociocultural, mas o caráter reflexivo e terapêutico do teatro, cujas origens remontam à fase reparadora do drama social, precisa recorrer às fontes do poder freqüentemente inibidas na vida do modo indicativo da sociedade. A criação de um espaço liminar separado, qua- se-sagrado, permite uma busca de tais fontes. Uma fonte desse excessivo meta-poder é certamente o próprio corpo liberado e disciplinado, com seus múltiplos recursos não explorados de prazer, dor e expressão. Uma outra fonte encontra-se em nossos processos inconscientes, tais como os que ocorrem em estados de transe. Trata-se de fenômenos semelhantes aos que freqüentemente encontrei na África, onde senhoras idosas, magras e mal-nutridas, entre um cochilo ou outro, dançam, cantam e realizam atividades rituais durante dois ou três dias e noites sem parar. Penso que um aumento no nível de estímulo social, a despeito de como é produzido, pode liberar fontes de energia nos participantes individuais. $\mathrm{O}$ recente trabalho sobre a neurobiologia do cérebro (ver d'Aquili, Laughlin \& McManus 1979), mostra, entre outras coisas, como as "técnicas de conduzir o ritual (incluindo condução sônica, por exemplo, com instrumentos de percussão) facilitam o domínio do hemisfério direito, resultando em experiências atemporais, não-verbais, e gestalt, diferenciadas e únicas quando comparadas com as manifestações da funcionalidade do hemisfério esquerdo ou a alternação dos hemisférios" (Lex 1979: 146).

Meu argumento tem sido que a antropologia da experiência encontra, em certas formas recorrentes de experiência social - entre elas, os dramas sociais -, fontes de forma estética, incluindo o drama de palco. Mas o ritual e sua progênie, com destaque às artes performativas, derivam do coração subjuntivo, liminar, reflexivo e exploratório do drama social, onde as estruturas de experiência grupal (Erlebnis) são copiadas, desmembradas, rememoradas, remodeladas, e, de viva voz ou não, tornadas significativas - mesmo quando, como acontece freqüentemente em culturas declinantes, "o significado é de que não há significado". $\mathrm{O}$ verdadeiro teatro é a experiência da "vitalidade intensificada", para citar Dewey novamente. 
"Em seu auge, significa a completa interpenetração do eu e do mundo de eventos e objetos" (citado em McDermott 1981: 540). Quando isso acontece numa performance, o que pode ser produzido é o que d'Aquili e Laughlin chamam de um "fugaz estado de êxtase e sentido de união (com duração freqüente de somente alguns segundos) [que] pode ser descrito como um arrepio - nada mais que isso - que desce pelas costas até um certo ponto" (d'Aquili et al. 1979: 177). Um senso de harmonia com o universo se evidencia e o planeta inteiro é sentido como uma communitas. Esse arrepio, contudo, deve ser conquistado, para tornar-se uma "consumaçáo". Isso, após lidar com um emaranhado de conflitos e desarmonias. É o teatro que melhor exemplifica o dito de Thomas Hardy: "se há um caminho para o melhor, ele exige um olhar de frente para o pior". As transformaçóes rituais ou teatrais não ocorreriam de outra forma.

\section{Referências bibliográficas}

D'AQUILI, E. G., LAUGHLIN, JR., Charles D., and McMANUS, John. (eds.). 1979. The Spectrum of Ritual. New York, Columbia University Press.

DEWEY, John. 1934. Art as Experience. New York, Minton, Balch \& Co.

DILTHEY, Wilhelm. [1914]. Selected Writings. Ed. H. P. Rickman. Cambridge, Cambridge University Press, 1976.

LEX, Barbara. 1979. "The Neurobiology of Ritual Trance”. In D'AQUILI, E. G., LAUGHLIN, JR., Charles D., and McMANUS, John. (eds.). The Spectrum of Ritual. New York, Columbia University Press.

McDERMOTT, J. J. (ed.). 1981. The Philosophy of John Dewey. New York, Putnam's.

MYERHOFF, Barbara. 1979. Number Our Days. New York, Dutton.

TURNER, Victor. 1982. From Ritual to Theatre. New York, Performing Arts Journal Press. 